\section{SOCIAL, CULTURAL AND POLITICAL ASPECTS OF NATIONAL IDENTITY}

\section{Introduction}

Nowadays complicated problem of national identity is one of the mental occupations and apprehensions of too many religious, political, economical, cultural thoughtful and governmental men and artists. Today identity's problems are fate maker. National identity is any kinds of probed action, especially social action and it is necessary bet for development. Having especial and independent identity for the individuals of a country is not only the basic elements for individual living, but it makes meaningful social and individual life of human and give it a special dynamism. In order to receive to permanent development in a country, we need to generate effective human force with necessary cultural, social and economical tends.

The balance in the society is obtained while the members of the society seek for common social, political and economic activities based on a common identity. Today the modern and developed societies have obtained their common identity while the underdeveloped counties still facing ethnical, and tribal conflicts.

The contemporary world is considerably globalized and national identity plays a vital role in global solidarity and belonging to the greater identities at the world level. In the modern time the national identity is usually determined by two primary opposite forces: globalization and localization processes. Both phenomena are simultaneously shatter the national identity and strengthen it through global and local communication processes. The national identity crosses the ethnic and tribal identities and results to the distinguishing between different citizens of the countries based on their civil characteristics. Each human society is include various ethnical, tribal and racial individuals and groups and each of these groups has their own particular identity which sometimes results to the social conflicts and lead to the social crises. In order to prevent crises; societies require the common identities which include all ethnical and tribal groups and bring social balance.

\section{Main body}

\section{National Identity}

Identity is one of the basic concepts in which social scientists have been interested during last decades. Social identity, particularly 
national and ethnic identities as its forms, is widely applicable topic that determines harmony, unity, integrity of the people and the nation. Every community and every individual as known accept collective ideas and norms forming their own identity, which is contributed to the unity of society.

National identity means loyalty and attachment to common elements of society and it is among the identified political borders. Yusufi beliefs that inside a society, balance of attachment and loyalty of members to any of mentioned elements and symbols identify their severity sense of national identity [1].

National identity by sociological point of view is a kind of loyalty sense into society's national commons that causes unity and solidarity. And it is contains of different dimensions of national, religious, social, and human subculture and factors of flexibility and being native of formed dimensions are its principal characteristics.

National identity is one of the most important evolutions of $20^{\text {th }}$ century. In this case, the procedure of countries independence moved faster, when nations formed their wants, freedom, sovereignty and power. This desire will form national sovereignty or national government. On other hand, national culture is national identity bankroll; hence, in order to receive to national identity reorganization of national culture is necessary.

Eventually, it is possible to remark that national identity is collection of positive tendency and theory according to causes and elements. Identity and same samples are as a basic political unit in any countries and it is the base of national identity, sense of commitment and attachment to unity of society, that it is more meaningful on national borders and scope [2].

In sociology there are more effective samples for declaration of elements and dimensions of national identity, division of national identity elements in to social, historical, political, religious, and cultural ones. And lingual elements are more important, therefore formation of national identity on its scope will become more completed and clear.

\section{Social Dimensions of National Identity}

Social dimension of national identity is interrelated with quality of individual and social relationship with big social system. Attachment sense to national society is the substance of friendly and emotional relationship of social dimension [3, p: 28].

Belief in existence of national society is individual commitment to national community, accepting each other as a fellow-country. Positive look to others related to nation, believes into national community roots, credence about fate and future of society, and willingness to pay the necessary coasts for his/her membership and continuity is essential aspects [4, p:73].

Historical Dimension of National Identity

Historical evolutions are completely effective on formation of attachment and interest sense into identity collection. Historical defeats, victories, sweetness and bitterness of a nation always are by interest of people and it is effective on public ideas.

Historical dimension of national identity consists of common awareness of individuals of a society about the historical past and it is interest sense. This sense relates together different generations of a nation.

Awareness about the historical past and fixation to it has three dimensions: first, historical knowledge means awareness about the important events and historical personalities. Second, fixation means existence of positive and negative senses about the events and positive and negative personalities. Third, historical efforts mean emphasizing on historical events [3, p: 29].

\section{Cultural Dimension of National Identity}

Culture is as identity card of a nation and cultural identity is as historical document of tries and creativities, proud and in common it counts as ups and downs prideful or warning of past and present of a nation. After national identity it denotes on common cultural heritage of a nation that has a common agreement to it. This common cultural heritage contains collection of architectural work, life methods, traditions, fests, myths, samples and symbols, customs, oral literature, native and national arts, clothes, wearing methods and such elements. Geography and social components are the most important causes of lingual variety. In sociology, language is the clearest and most important of human cultural characteristics.

Language is the base of cultural demands and facility of culture, politics, and power identifier. Supporting of national identity is one of language outputs. Even if there are another divergent forces [5]. Language of a nation is not only dialogue instrument but it is a facility for thinking, world theory of social action, social identity and huge and tiny relationships with each other, around the world and past, present and future tense [4, p:77].

\section{Political Dimension of National Identity}

Individual fixation of a nation is the base of legitimating force and political system that appears at the form of government, called political dimension of national identity. Hence, legal or physical fixation into a political system does not form the political dimension of national identity, but fixation and agreement sense into base of worthwhile 
and political system came to verify and run the agreement. We can conclude the political dimension components on national identity as follow: Political knowledge or awareness about the political system manner, participation and supervision, interests to nation, learning to do political activities, trust and confidence on political system, agreement on legitimating and effectiveness of government and loyalty on political associations [3,p:30].

Aspects of Socio-Cultural National Identity Problems

1. Subcultures intension and molest duplication

Culture element contains a wide area of spiritual and material concepts. It is counted as a basic factor in concept of national identity. Culture contains many collection of traditions, values, customs, behaviors, norms, believes, different forms of relationships, living method, production and utilization sample, particular arrangement and spiritual and material systems.

Hence, distinguishing and separation of subcultures is preventer of completion and genesis of national symbols and samples. Symbols and myths are the sample of unity and cultural sharing of a national society, in a multinational culture area like Afghanistan. It is crossing on tribal, ethnical and familial circles. In so doing we could not point out an agreement and unity symbol that that be honorable for all the parties, groups and tribes of Afghans on their lives and social relationships. Primarily myths and symbols have been recognized as the sample of national, racial, and local distinctions. Insisting and partiality on ideas and samples of national culture, impressible of environmental conditions, diseconomy and low level of general literacy, create a wide field for tribal and factional culture to conquest on common national culture.

\section{Religious and Races Contrasts}

Referring and tendency to necessary values of religion, helps for creation of common conventional and social norms in addition reliable national unity and national opinion. Output of this revision secure and guarantee social discipline, cultural fruitful and consistence and national continuity and permanency.

Religious alienation is a prevalent and dominant phenomenon which set tension and contrast social relationships of different religious followers. In this order sensitivity and defiance of religion followers to each other, decrease the opportunity of national solidarity and continence for the wishes of national big categories. Putting considers and religious courses as criteria for social relationships and interpretation of common culture from close idea and jealousy religious sensitive, limits cultural common into national arena. Passion, irrational and permanently behaviors are outputs of these actions among verities of society in some Islamic countries.

3. Structural Rule of Language on Determination of National Identities and Problems

According to semantic and symbolic characteristics which contain the complicated system of language, the cultural and social phenomenon is the most important element of national identity that concludes value abilities and lives, dynamic and resistance works on formation of culture. Realization and understanding is the basic needs of a human society and principle bet for cultural continuity on nation, and it is one of the unchangeable usages of language. Series and roots of too many circles and symbols of national culture and social collaboration and convergence have tightly related with language element. Common language can continue human continuum of a country in a cultural scope, permanency and organic continuity and secure and condescend level of social reproduction and deal in a civilization arena.

Experience has shown that lingual and accentual multiplicity in a colonial land, with complicated social formation especially lack of political system, has a damage rule on completion of political system and conflation of national society. In this case, accentual multiplicity increase social contrast relationships and do not create the environment for cultural exchanges and agreement. This procedure can be a big problem and damage genesis of common culture.

Accentual differences in some countries which contain variety and complicated combination put wonderful effect on separation and alienation of cultures and social and national characteristics of residents of a region. Jealousy interest of accent and tribe practically put the speakers of different accent into kinds of cultural simulation and opposition and make bigger social problems.

\section{Tribal Problems}

One of the reasons of identity crises formation is the problem of going to extremes orientation into local and tribal collective identities instead of attraction into national and social collective identity. This identity crises and its pursuit common collective identity weakness pave the way for individuals going out and influence of external cause at the level of society. On its term it is effective on intense of identity crises. This damage is the result of plurality and contrast of personality. Social system and plurality contrasts especial weakness system, personality system and national and common collective system at the level of society. 


\section{Anomy and Abnormal}

According to Durkheim's the period appears in society which is the first causes of unity face with problem among them. This is the situation which from one side society complications are going on and create new groups and breaks traditional solidarities. From the other hand an new system is stable; this is the phase that the abnormal or allotropy of norm and situations will removed and will born many other value. This systems appears different value which is most important evolution which specify new world and bring the anomy situation with itself. Political and social evolutions are the reflection of anomy situation into like these societies.

Political aspects of national identity problems

Party course victory on national attachments

Power monopolization with motivations and characteristics of party, inheritable and familial, play many different social and political fates for society. This monopoly is mixed by despotisms, often time it was the cause of losing opportunities, and it burdened unbalanced politics in the society level as stated form of party politic on national treatment. Nature and fruit of this despotism, is the cause of genesis and spread of invalidity, regardless and contrasts among different groups of people. Moreover, it is conducive and deeper distances between groups of people and despotisms parties. Collection of these causespolitical instability and crises on social relationships, political dispersal and active social gap among the residents of a country. For the reason that, party identities practically encounter with national identity and prevents from genesis and completion of national proud and thought among many different society spectrums.

Political despotism and contrast of government and nation

Opinion has shown that in some countries political systems often time are not with humanity bases and their history have lots of witness about the conflict of political system and people mass.
Political rulers often pursuit political settlement by recourse in to specific ideology and different categories of people. These system by aggression and transfusing into different social and individual arenas caused to waste legal freedoms of society. In this condition contrast of political system values and social system and cultural system values had the basic rule on appearing on national identity crises.

\section{Conclusion}

National senses and sentiments were born dependently that a society has common believes, myths and posses to them. Hence dependencies balance are more enrich, compressed, deep, and further as same as, national sentiments. Mobilizing and sense compression are more aim-oriented, grandeur and more evergreen for proving and creation of national solidarities. Creation and assembling of this opportunity and space need to factors and subtractions which one of them is the cause of national validity and reconstruction of trust among the citizens of nation. In this procedure, parties, groups, and different categories of society must find the sense of dependency, well advised posses and hunky dory into nation and country. Secondly, strengthen of validity, moral and reciprocal equality among the different categories of nation. That is why we can be hopeful for the creation of opportunities and necessary insights for geneses and expansion of national soul and find real and factual crystallization. In any case it seems that national identity constructing is the step for national development, the solving of national solidarity crisis makes procedure of building of well-founded government more fruitful. Rise of integrate cultural values, design of social patterns and common collective sense system would allow establish and reconstruct the nation. In case of lack of these resources a nation making process would be too difficult and could face with too many problems.

\section{References}

1 Yousefi A. Inter-ethnic relations and its impact on national identity in Iran: a secondary analysis of data from scientific surveys // Scientific Studies. - 2001 (1380). - Quarterly, Volume 2, N8. - P. 17.( in Persian)

2 Mirmohammadi D. Discourses on national identity in Iran. - 2004 (1383). - Tehran: Institute of National Studies, p. 26. ( in Persian)

3 Goudarzi H. The basic concepts of Ethnic Studies. - Tehran: Iranian civilization, 2006 (1385), 300 p. ( in Persian)

4 Abolhasani S.R. Determining and measuring the components of Iranian identity. - Tehran: Center for Strategic Research, 2009 (1388), 356 p. ( in Persian)

5 Kaviani R. Regionalism from the perspective of geopolitics in Iran. - Tehran: Center for Strategic Studies, 2010 (1389), p.67.( in Persian) 